\title{
Association between China's digital economy and labor education in post-pandemic of COVID-19 based on neural network
}

\author{
Li, Yongkang* \\ School of Marxism, Wuhan University, Wuhan, Hubei, P.R. China
}

\begin{abstract}
In post COVID-19 era, labor education plays an indispensable part in China's digital economy, while the digital economy will redefine the labor education at the same time. From the Marxist theory, latest data and survey results, we portray the logic relationships, mutual impacts between digital economy and labor education. Our research indicates that free development of all human beings is the common value shared by the digital economy and labor education. Labor education can cultivate the abilities of competition and cooperation, form the proper digital economy values meanwhile, which is essential to hedge the negative impacts of digital economy on labor and employment. Labor education comprehensively promotes the digital labor abilities of all laborers in the path with Chinese characteristics. The boom in digital economy and the refocusing on labor education will enable China to cope with the rising risks and challenges in a more diversified and flexible way among this highly uncertain world.
\end{abstract}

Keywords: Digital economy, labor education, COVID-19, neural network

\section{Introduction}

Education has always been an indispensable part of the whole economy, and the economy will have an impact on education at the same time [1]. The COVID-19 pandemic has fundamentally changed the world as we know it. The whole world is on the risk of another Great Recession and severe public health crisis. As a promising representative of the fourth revolution of science and technology, digital economy is considered to bring new dynamics to China's epidemic prevention and control as well as economic and social rebooting, which has been

${ }^{*}$ Corresponding author. Li, Yongkang, School of Marxism, Wuhan University, Wuhan 430072, Hubei, P.R. China. E-mail: 55479659@qq.com. introduced and promoted with great expectations $[2,3]$. Therefore, two important policies have been adopted by the Chinese government, one is Digital Transformation Partnership Initiative aimed at accelerating the development of digital economy, and the other is Opinions on Comprehensively Strengthening labor education in colleges, middle and primary schools in the new era [4]. What are the logics behind these two policies? How can digital economy and labor education mutual influence each other? What future will digital economy and labor education reshaped?

To answer above questions, our research uses the latest data and the result of questionnaire survey based on the 1,624 students from Hubei Province in Wuhan University. Portraying the background of two new policies and explaining the relationships 
and influences between digital economy and labor education both in theory and literature [5]. This study outlooks for the future and discusses the possible limitations of digital economy.

\section{Background: some basic concepts, tendency and survey data}

\subsection{The concepts of digital economy and labor education}

Digital economy is a new form of economic and social development after agricultural economy and industrial economy [6, 7]. The G20 Digital Economy Development and Cooperation Initiative launched by 2016 G20 Hangzhou Summit had defined digital economy as below. Using digital knowledge and information as key production factors, taking modern information network as important carrier, digital economy is a series of economic activities with the effective use of information and communication technology (ICT) as an important driving force for efficiency improvement and economic structure optimization [8]. As it continues to rapidly evolve, the connotation and extension of digital economy are still developing. Labor education is an important part of the socialist education system with Chinese characteristics.

\subsection{Accelerated development of digital economy during the lockdown}

According to the China Novel Corona virus Pneumonia Impact on Chinese Enterprises issued by the United Nations Development Program (UNDP) China in April 2020, it is estimated that online office, online education and online games have increased significantly, reaching 537\%, $169 \%$ and $124 \%$ which is shown in Fig. 1.

The reality is that COVID-19 pandemic, being not the trigger or starting point of China's digital economy, has merely reinforced the existing trends [9]. According to the Digital Economy Index of China released by Caixin Insight in April 2020, it is obviously that the digital economy index of China has been on the trend of accelerating development since 2016 which is shown in Fig. 2.

We can see the specific development of each industry more clearly, by dividing the digital economy industry into Internet, big data and artificial intelligence (AI) industry [10]. Among them, the investment in the Internet industry rose sharply in April after the outbreak, while the investment in the artificial intelligence industry and big data industry slightly lower than the previous month which is shown in Fig. 3.

The integration of digital technologies with industry, business, service and finance are respectively embodied in Industrial Internet, Smart Supply Chain, Sharing Economy and Financial Technology (Fin Tech). According to the input of labor, capital and science \& technology in above four fields, we can precisely measure the degree of integration. In April 2020, the ring growth of Industrial Internet, Smart Supply Chain, Sharing Economy and Fin Tech increased significantly, with the ranges of $57.6 \%$, $63.1 \%, 54.8 \%$ and $44.2 \%$ respectively which is shown in Fig. 4.

\subsection{Accelerated development of digital economy during the lockdown}

The unprecedented lockdown and quarantine make many of us realize that even if meeting the needs of survival and safety, we will still fall into a sense of emptiness and meaninglessness without labor. Moreover, the basic labor abilities are unfortunate people's bottom protections which can shelter them from business failure and offering an opportunity to comeback. For example, cities around China started allowing people to set up roadside booths or food stalls on streets on a regular basis over the weekend. Under the rule of social distancing, although digital technologies show great advantages in assisting policy-makers decision-making and improving labor productivity, it is still inseparable from human basic labor, such as the constructions and maintenances of digital infrastructures. Through the labor of the medical staffs, construction workers, volunteers, deliverymen, sanitation workers and so on, the indispensable and non-fungible functions of daily life labor, production labor and service labor have been re-recognized. Cultivating Marxist labor values including but not limited to love labor, respect ordinary worker, form labor spirits and habits etc. becomes a consensus of China's educational and political circles.

To accurately manifested the situation of Chinese college students' participation in labor during the COVID-19 pandemic, a questionnaire was conducted among 1,624 Hubei students majoring in medical vocational technology in Wuhan university in April 2020. The results showed that $88.66 \%$ of 


\section{Comparison of public opinion index between online office and online}
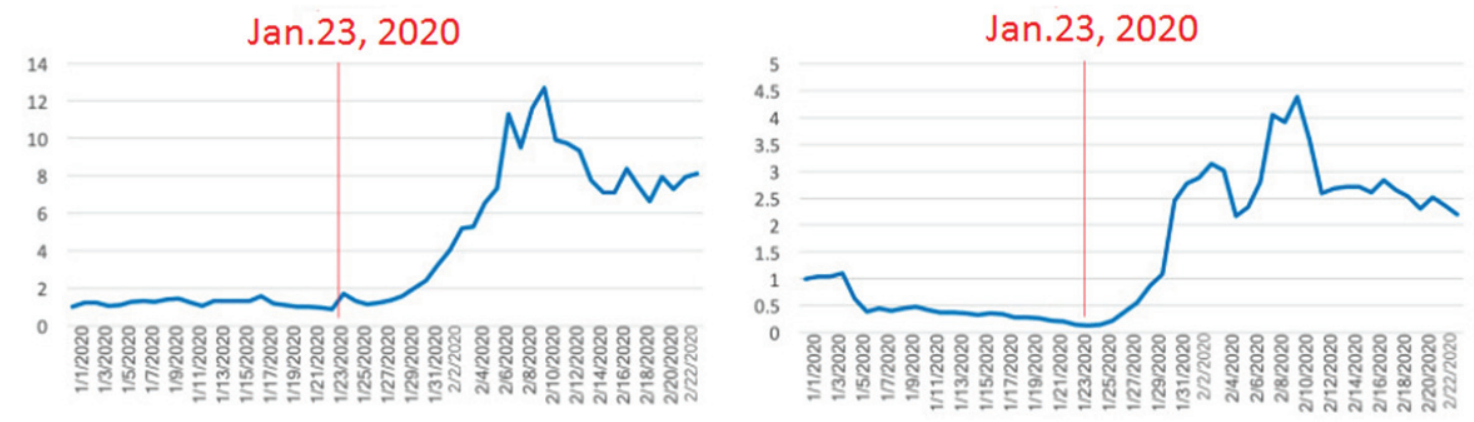

2020 Comparison of public opinion index between online video and online game
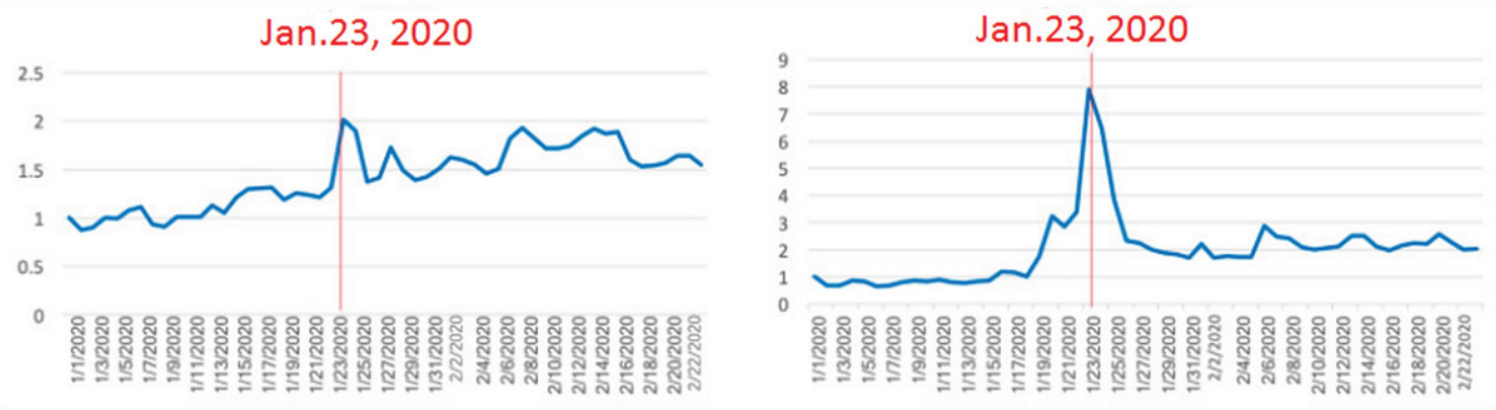

\section{Comparison of public opinion index between social and online e-commerce}
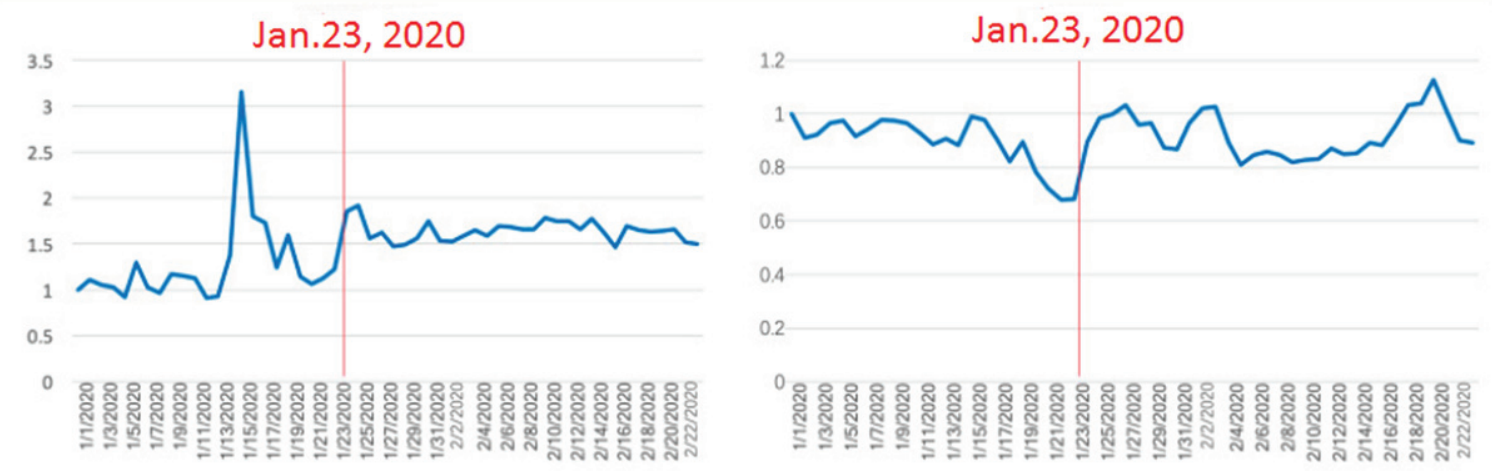

Fig. 1. UNDP: China novel corona virus pneumonia impact on Chinese enterprises.

the medical students were willing to register if the government recruited in emergency. $32.19 \%$ of the questionnaire respondents thought they were engaged in housework in the home quarantine period, but only $8.76 \%$ respondents participated in the COVID-19 prevention and control activities or related voluntary services. In response to the question "reasons for not participating in COVID-19 prevention and control, voluntary services or domestic works", $60.72 \%$ of the respondents chose the option "online classes occupied the time". According to the further interview with $42.2 \%$ of the respondents who answered "other reasons", even in the majors which emphasized labor education, these is a widespread preference on mental labor than manual labor. Lack of labor skills and labor willingness is severe in the questionnaire respondents. The phenomenon of 'unwilling to labor, unable to labor' do exist to some extent in parts of youth nowadays.

During the pandemic, the accelerated development of digital economy and the importance of labor education are highlighted. The Chinese government will speed up development of digital economy and strengthen labor education in the post-pandemic is 


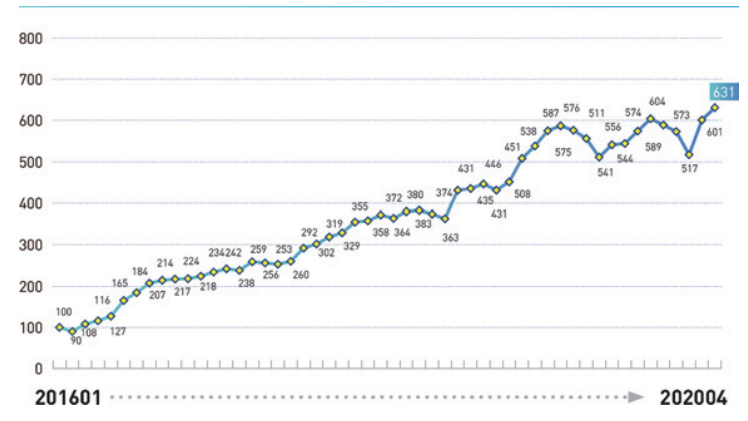

Fig. 2. Digital Economic Index 2020.04.

\section{China' s-Digital-Economy-Index:Internet;-AI'and-Big-data.}

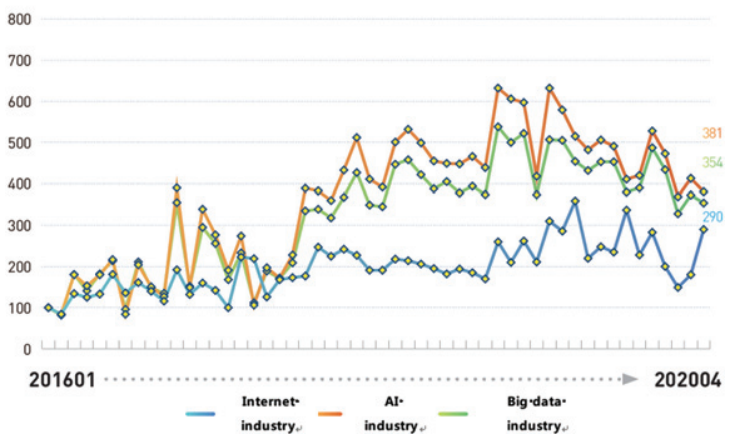

Fig. 3. China's Digital Economic Index: Internet, AI and Big data, 2020.04 .

\section{Industrial-'nternet, Smart-Supply-Chain,-Sharing-Economy-and-Fin-Tech}

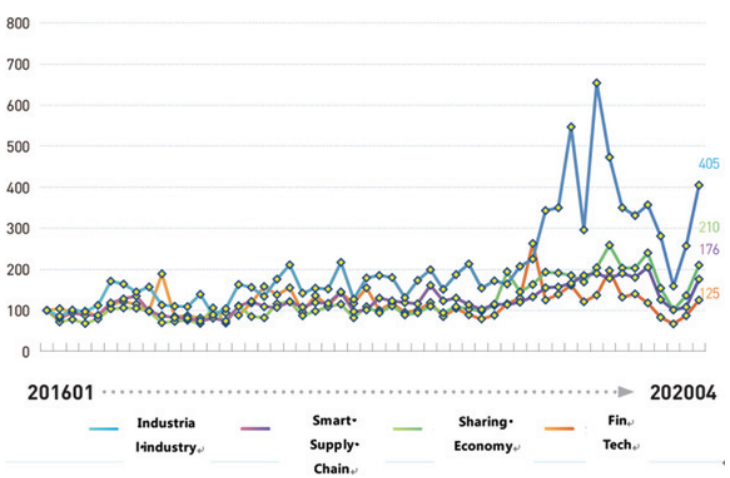

Fig. 4. Digital Economic Index: Industrial Internet, Smart Supply Chain, Sharing Economy and Fin Tech.

not the only intersection of them. It's more than that digital economy and labor education have some deep internal relationships and mutual impacts between each other.

\section{Digital economy and labor education: value orientation and mutual impacts}

\subsection{Common value of digital economy and labor education: Free and all-round development of human beings}

The main driving force of digital economy is digital technologies represented by big data, cloud computing, $5 \mathrm{~g}$, artificial intelligence (AI), etc. With the application of digital technologies, people deepen their understanding of the objective world, create new knowledge and discover new laws. Indeed, through the digital labor energized by digital technologies, it is possible to improve total factor productivity (TFP), optimize the allocation of resources, further emancipate and develop productive forces. In socialist countries such as China, due to the public ownership of means of production, the value orientation of developing digital economy is to realize the free and all-round development of human beings.

Different from capitalist economy, labor education is always an important part of the socialist economy and education system with Chinese characteristics. Labor education's theoretical foundation is Marxist labor theory. In effect, Marx outlined the future communist society in Die Deutsche Ideologie like this, "with the elimination of private ownership and labor alienation, the opposition between urban and rural areas, between physical labor and mental labor will also be eliminated. Labor will become a real independent activity of human beings, and everyone will realize the free and all-round development."

From the above analysis, we can infer that the China's digital economy and labor education have the common value which is oriented by the Marx's concept of labor. In response the post-pandemic, China promptly launched the plan of accelerating the development of the digital economy and strengthened labor education, whose ultimate purposes are to improve total factor productivity, produce 'real value' (not the fictitious capital), create new industries and jobs (not on the contrary), meet people's increasing material and spiritual life needs, and promote people's free and all-round development.

\subsection{Digital economy: overall impact on labor and employment}

The pandemic has widened divides in the labor market. The statistics show how different segments of the population have been affected by the pandemic. 
Besides some evidences are clear that the digital economy has widened China's existing divides between professionals, low-paid labor workers and the young. It crafts a systematic critical theorization of labor as performed in the capitalist ICT industry. Relying on a range of global case studies. Fuchs sheds light on the labor costs of digital media, examining the way information and communication technology (ICT) enterprises exploit human labor and the impact of this exploitation on the lives, bodies, and minds of workers.

Some of Fuchs' inferences have been evidenced by Chinese researchers [11]. According to newly published research-The Development Report on Chinese Youth: Hummingbirds Hovering between Urban and Rural Areas. This report shows that the courier has become a true portrayal of the hard work of the new generation of workers in digital economy. Most of them are from rural areas, and their general education is not high, work alone and on-line at any time with uncertainty. It can be seen that, no matter it is industry digitization or digital industrialization, digital technology hardly changes the contradiction between labor and capital. In capitalist accumulation, digital technology, as other disruptive innovation before, has become a new means to extract surplus value and monopoly profits, which improves the level of labor commercialization and labor exploitation. Under the veil of facilitation and entertainment, the distinction between on and off work has been quietly blurred by the digital technology intentionally or otherwise. For example, before the epidemic the widely criticized '996' (working from 9 a.m. to 9 p.m. for 6 days a week) model has been naturally replaced by '007' (24-hour standby for 7 days a week) model during the COVID-19 quarantine by an excuse of working at home. Not only implicit extension of working hours, the development of digital economy and digital technology will reduce jobs from the overall picture (though the digital economy, meanwhile, is also creating some new jobs). First and foremost, lots of medium or low intensity mental labor and the low-skilled physical labor are dying in the near future. As the trend continues, people's mental labor and physical labor will become ever more polarized. That is to say, with the development of digital economy and technology, human beings have not yet been liberated from the heavy and tense labor as far as the present situation. On the contrary, signs indicate that laborers and labor have been further alienated and commercialized. As robots and other computer-assisted technologies take over tasks previ- ously performed by labor, evidences show that robots may reduce employment and wages, through analyzing the effect of the increase in industrial robot usage between 1990 and 2007 on US local labor markets.

It believed that private ownership led to the alienation of labor, and the fundamental way to solve the alienation of labor was to eliminate private ownership. Due to the underdevelopment of productivity, China still has a long way to go to eliminate private ownership. Under the function of market economy, the phenomenon of labor alienation is inevitable. We can only minimize the degree of labor alienation and its impact. In order to curb the possible negative effects of the development of the digital economy, on the one hand, China will expand the coverage of vocational education and vocational skills training, update and improve the skills of workers through government investment in labor education; on the other hand, according to the needs of different schools and learning stages, China will comprehensively strengthen labor education in primary and secondary schools, and stimulate them through "integration of industry and education" and "cultivation of scientific spirit" Develop creative labor ability and lay a solid foundation for creative labor. Sukhomlinsky, a famous educator in the former Soviet Union, proposed that labor skills are of more and more importance in the production of material wealth [12]. In a sense, it is more difficult to cultivate workers who can work creatively than to cultivate mental labor experts. These two measures of the Chinese government will help to increase the proportion of labor in distribution, fully tap people's labor potential, create more digital technology application scenarios and jobs, and avoid the further expansion of the gap between the rich and the poor due to the development of the digital economy.

\subsection{Labor Education: enhance the sense of competition and cooperation and cultivate correct values of digital economy}

Compounded by the COVID-19 outbreak, the world is at the risk of economic recession, protectionism and involution. Several major countries represented by China and the United States have launched fierce competition in the field of digital economy. In the final analysis, the competition among countries is the competition among talent teams of all countries, which requires not only knowing how to achieve cooperation in the team, but also having a high sense of collective honor. Elite schools 
in western developed capitalist countries, such as Ivy League in the United States, Russell Group in the United Kingdom and so on, pay great attention to the cultivation of students with athlete background.

In fact, through physical education to cultivate the competitive ability, physical quality and sense of class belonging of the elite, realize the reproduction of the ruling class. However, socialist countries (such as China, the former Soviet Union, Cuba, etc.) tend to train "socialist builders and successors" generally through labor education, such as cultivating collective sense of honor through physical labor, cooperation and division of labor technology, necessary physical quality and enhancing competitive consciousness through labor competition. The scale and complexity of human cooperation needed for the research and development of $5 \mathrm{G}$, chip technology, Internet of things and other digital technologies are far greater than the previous three industrial revolutions, requiring digital workers to have a high degree of coordination and cooperation ability. The "winner takes all" effect of digital economy makes the leading countries and industry-leading enterprises occupy most of the market share, so the competition between countries, enterprises and enterprises is extremely fierce. Compared with the elite physical education in the west, labor education is more suitable for China's national conditions and more inclusive and equal.

The outbreak of digital economy further promotes "house culture", consumerism, and digital addiction and so on. The Internet makes it possible to meet all kinds of daily and spiritual needs without leaving home. During the epidemic period, social isolation may permanently change the behavior of consumers and become an "otaku" to resist socialization. The accurate identification of potential customers based on big data analysis and the convenience of online loans have contributed to consumerism. Some teenagers view life from the perspective of pure consumption, cannot find their life goals, and lose their values. Through algorithm capture, short video software can quickly depict, understand and learn users, and then start to push to users continuously, and make users addicted to digital through active "feeding". In 2018, the World Health Organization has listed the game disorder (addiction) as mental illness, and short video users can't stop this addiction. According to Marxist theory, "the mode of production of material life restricts the whole process of social production, political life and spiritual life. It's not people's consciousness that determines people's existence, on the contrary, it's people's social existence that determines people's consciousness. “ Participation in labor, especially physical labor, can enhance people's sense of existence, participation and significance in the real society, promote people's socialization and affect people's spiritual life, and feel the satisfaction and enrichment brought by labor in the process of labor creating value and labor serving the society, so as to help teenagers resist the erosion of consumerism and prevent their addiction to the virtual world and digital addiction Return to the right track of digital economic values.

\section{Conclusions}

The pandemic of new coronavirus and social isolation around the world have further accelerated the development of digital economy. Like the first three industrial revolutions (steam technology revolution, electric power technology revolution, computer and information technology revolution), the fourth industrial revolution represented by digitalization will greatly change human labor. Workers take digitalization as methodology to transform their labor, improve total factor productivity, and promote the liberation and development of productivity. Under the premise of public ownership of means of production, the development of digital economy and digital technology can promote the realization of human freedom. Although the digital economy will create some new jobs and jobs, it will further polarize physical labor and mental labor as a whole, and the general mental labor and physical labor will gradually reduce. No matter digital industrialization or industrial digitalization, China's digital economy will usher in more fierce competition and higher level of cooperation at the international and domestic levels.

As a response, China will increase investment in labor education through government intervention, improve the human capital of future workers, increase the proportion of labor in distribution, and hedge the negative impact of the development of digital economy on employment. Labor education aims to cultivate socialist builders and successors in a way suitable for China's national conditions, and comprehensively promote the improvement of digital labor capacity of all workers. The digital economy also has its limitations. One is the lag of law and regulation. The widespread use of digital technology in epidemic situation not only improves efficiency and promotes innovation, but also raises concerns about new problems such as personal privacy disclosure, information 
security, network violence, data monopoly, etc., while laws and regulations are often lagging behind the emergence of problems, and in addition to laws and regulations, digital ethics should be supplemented to restrain from the moral level; second, the risk of getting rid of the real to the virtual.

The digital economy should be closely integrated with the real economy, serve the development of the real economy, and avoid the hollowing of the real economy and the economic bubble caused by the economic finance before the failure. Third, the digital dependence of the digital economy. The data on which the digital economy is based is the representation of the past. Blindly superstitious about numbers but not aware of them are losing a lot of information in every step from production, collection, analysis to interpretation. Relying on numbers to make decisions on a highly uncertain world will cause conservatism and mistakes. Labor education can arouse the recognition of digital ethics, the awe of labor creation, and the return of people's common sense and intuition. The combination of digital economy and labor education will help China to deal with the risks and challenges in an increasingly uncertain world in a more diversified and flexible way.

\section{Acknowledgments}

This paper is supported by the "Research on the construction of new information infrastructure in Wuhan" issued by Wuhan Economic and Information Bureau, 2020.

\section{References}

[1] L. Zhang and A.Y. Fung, Working as playing? Consumer labor, guild and the secondary industry of online gaming in China, New Media \& Society 16(1) (2014), 38-54.

[2] H. Ono, Digital Inequality in East Asia: Evidence from Japan, South Korea, and Singapore, Asian Economic Papers (2005), 4

[3] S.-C. Yoon, Servicization with skill premium in the digital economy, Journal of Korea Trade 22(1) (2018), 17-35.

[4] A. Fish and R. Srinivasan, Digital labor is the new killer app, New Media \& Society 14(1) (2012), 137-152.

[5] A. Greenhill and G. Fletcher, Laboring Online: Are There "New" Labor Processes In Virtual Game World by Anita Greenhill and Gordon Fletcher, Journal of the Association for Information Systems 14(11) (2015), 672-693.

[6] R.A. Ghosh, P.A. David and Y. Benkler, CODE: Collaboration and Ownership in the Digital Economy, Quarterly Journal of Economics 54(3) (2005), 527-534.

[7] N. Ettlinger, Open innovation and its discontents, Geoforum 80(MAR.) (2017), 61-71.

[8] A.J. Ravenelle, Antisocial Media: Anxious Labor in the Digital Economy, Social Forces (2) 2.

[9] B. Badarevski, Reducing the digital gap in the labor market: for more e-inclusive workplaces, Journal of Social Policy 201219.

[10] J.A. Wilson, Cosmopolitan Stars, Interactive Audience Labor, and the Digital Economy of Global Care, Television \& New Media 15(2) (2014), 104-120.

[11] B. Newman and E.T. Liu, Perspective on BRCA1, Breast Disease 10 (1998), 3-10.

[12] D.F. Pilkey, Happy conservation laws, in: Neural Stresses, J. Frost, ed., Controlled Press, Georgia, (1995), 332-391. 